\title{
The ineffectiveness of shock avoidance under short and long R-S intervals
}

\author{
HARRY M. B. HURWITZ and THOMAS F. HERRMANN \\ University of Guelph, Guelph, Ontario, Canada
}

\begin{abstract}
Six rats were trained in 20 sessions to avoid shock under a free operant, shock postponement schedule. The R-S interval was 20 sec. Each subject was then tested for five consecutive sessions under each of the following R-S intervals: 5, 10, 20, 40, and $80 \mathrm{sec}$. Although the rates of responding increased as an inverse function of the size of the R-S interval, the rate of shock avoidance was bitonic. The percentage of shocks avoided was low under short and long intervals and relatively high in the middle range of R-S intervals. An analysis of pituitary-adrenal activity failed to show a difference attributable to the number of shocks received per session. The results are accounted for in terms of an interaction between species-dominant behavior in a threat situation and the behaviors demanded by the avoidance schedule.
\end{abstract}

This paper concerns the well-established phenomenon that with a free operant avoidance procedure the rate of responding increases as the safety interval created by each response decreases. The question examined was whether the existing experimental evidence supports the attendant claim that such systematic changes in the rate of responding also reflect changes in shock avoidance. We shall present experimental evidence that contradicts this widely held assumption. We shall show that, on the contrary, avoidance (i.e., the percentage of scheduled shocks that have been avoided) cannot be predicted from the rate of responding.

The free-operant avoidance training procedure was first described by Sidman (1953) some 20 years after Warner's classic experiments on avoidance conditioning in the rat (Warner, 1932). Although Warner, and others in subsequent studies (Munn, 1950), used a discrete trial procedure, Sidman developed a method for testing subjects continuously. The procedure involves presenting brief shocks at regular intervals, referred to as the S-S cycle. The cycle can be interrupted by a response, $R$. The period of safety produced by each response, which is usually longer than the S-S interval, is referred to as the R-S period. By responding at intervals less than the value assigned to $R$ $S$, all shocks may be avoided. Although total avoidance has occasionally been observed in monkeys, rats typically do less well, as indicated by the literature on the "warmup effect" (Hineline, 1977). Irrespective of the species used, the outcome of the procedure is so reliable (as Sidman's, 1966, and Hineline's, 1977, extensive reviews have shown) that the phenomenon has attained the status

This research was supported by grants to each author from the Natural Science and Engineering Research Council, Canada, and a small grant from the Research Advisory Board of the University of Guelph, 1980. The assistance of Jill Lyons is gratefuly acknowledged. Reprints may be obtained from either author, Department of Psychology, University of Guelph, Guelph, Ontario, Canada N1G 2W1. of a "law of behavior" represented by the formula $r=$ $f(R-S)$, where $r$ refers to the rate of responding.

A different prediction follows from the consideration that changes in the R-S interval may affect the aversiveness of the situation (Herrnstein \& Hineline, 1966). Since short R-S intervals increase the opportunities for shock, aversively controlled behavior may be affected. According to one version of the role of motivational factors in behavior, increased aversiveness should facilitate avoidance. A different interpretation, first stated by Yerkes and Dodson (1908), is based on the assumption that high and low aversiveness may interfere with appropriate action, producing a bitonic relationship (Church, 1970).

We decided to look further into this issue. Postsessional blood samples were taken from our subjects and analyzed for levels of corticosterone. These levels serve as an index of the activity of the pituitary-adrenal system. The test is widely regarded as a suitable test of a subject's state of arousal and stress (Bassett, Caincross, \& King, 1972; Hennessey \& Levine, 1979). One would expect long R-S intervals, which result in low frequency of shock, to be inversely correlated with stress. Consequently, one would predict that long R-S intervals result in low levels of corticosterone.

\section{METHOD}

\section{Subjects}

Six 120-day-old female hooded rats of the Long Evans strain were obtained from the colony bred and maintained in the Department of Psychology at the University of Guelph. They were housed individually and fed ad lib. The laboratory was on a cyclic lighting (10 $\mathrm{h}$ dark, $14 \mathrm{~h}$ light) regimen. The temperature was maintained at $30^{\circ} \pm 2^{\circ} \mathrm{C}$ ).

\section{Apparatus}

Two modified LVE operant chambers were used. Each chamber measured $23 \times 24 \times 24 \mathrm{~cm}$ and was equipped with a 5-cm-wide lever. The lever protruded $2.5 \mathrm{~cm}$ into the chamber. It was located 
$5 \mathrm{~cm}$ above the grid floor and in the center of one end wall. The grid floor consisted of $25-\mathrm{mm}$ stainless steel rods spaced $3 \mathrm{~cm}$ apart. A constant-current shock generator (Campden Instruments, U.K.) was used to deliver a brief scrambled $(.5 \mathrm{sec}, .8 \mathrm{~mA})$ shock to the grids, lever, and metal walls of the chamber. The chamber was illuminated during the experimental session by a $12-\mathrm{V}$ ceiling lamp. Each chamber was housed in a large sound-resistant container whose exhaust fan provided a 76-dB masking noise.

\section{Procedure}

The subjects were transferred from the General Animal Holding facility to the laboratory 1 week before the experiment was begun. Each subject was given $1 \mathrm{~h}$ of free sessions of operant avoidance training. The sessions were run daily, but not on Saturday and Sunday. Shock was administered every $5 \mathrm{sec}$ (the S-S cycle). A leverpress interrupted the $S-S$ cycle and initiated a 20 -sec respite from the S-S cycle. Subsequent responses postponed the S-S cycle for $20 \mathrm{sec}$ from the time of response.

Each subject was trained for 20 sessions before it was assigned a different order of R-S presentation. This assured that the group data would be free from an order-of-presentation effect. The values of the R-S postponement interval used were $5,10,20,40$, and $80 \mathrm{sec}$. Each animal performed under each of these intervals for five successive sessions.

Since we were interested in the effect of shock on arousal, block samples were taken following the adaptation period to the laboratory (basal sample) and immediately following the 4th or 5 th session of each experimental block. These samples were obtained using procedures previously described (Davis, Memmott, MacFadden, \& Levine, 1976). The samples were analyzed via flourometric methods (Glick, Von Redlich, \& Levine, 1964) at Stanford University Medical School.

\section{RESULTS}

Final session records for each R-S interval were obtained of (1) the rate of responding per session, (2) the number of S-S cycle shocks, and (3) the total number of shocks delivered. By subtracting (2) from (3), a measure of shocks attributable to the elapse of R-S cycles, that is, of the number of unavoided shocks, was obtained. The basic measure of analysis was a repeated measures MANOVA, using blocks as the repeated measure. Subsequent analyses consisted of the $t$-crit test (Brunning \& Kintz, 1968) for significant difference between means and a trend analysis over intervals for each measure used.

The final day of baseline measures did not differ significantly from the final day of R-S 20 experimental session measures. These baseline measures will therefore not be displayed or used in the presentation or in the analysis of R-S data.

The results are presented in four sections, namely, in terms of (1) the rate of response, (2) the rate of shock, (3) the proficiency of avoidance, and (4) the analysis of corticosteroids levels.

The within-subject rates of responding per session (see Figure 1) were significantly different $[F(4,20)=93.1$, $\mathrm{p}<.0001]$ under different R-S intervals. In all cases, no effect was found that could be attributed to the order of $\mathbf{R}-\mathrm{S}$ exposure. The rates of responding increased as $\mathrm{R}-\mathrm{S}$ decreased. A trend analysis over intervals demonstrated that the inverse relationship was linear $[F(1,20)$

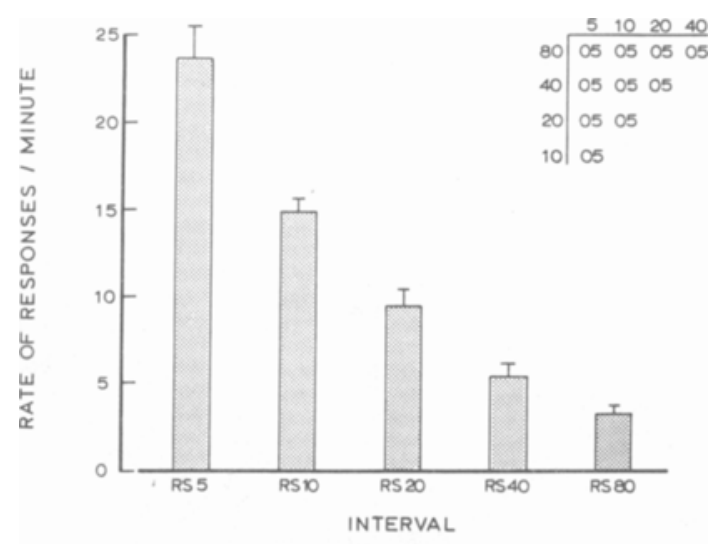

Figure 1. Rate of responses per minute as a function of the $R-S$ interval. The table of statistical significance shows a significant difference between each of the R-S values examined.

$=344.35, \mathrm{p}<.0001, \mathrm{~F}($ deviations $)(3,20)=0.12, \mathrm{p}=$ $.9]$ over the geometrically increasing intervals used. This finding is in concordance with Sidman's basic findings of an inverse relationship between the size of the R-S interval and the rate of response.

The shock data (see Figure 2) were analyzed by three different measures: (a) the total shocks per session; (b) the S-S cycles shocks; (c) shocks resulting from the elapse of R-S intervals. (a) The total number of shocks per session was found to be curvilinearly related to the R-S interval $[F(1,20)=18.7, p=.0003, F($ deviation $)(2,20)$ $=2.2, \mathrm{p}=.13 \mathrm{]}$, whose maximum number occurred when the R-S interval was $5 \mathrm{sec}$. (b) Shocks derived from the S-S cycle followed a cubic function $[F(1,20)=6.69$, $\mathrm{p}<.02, \mathrm{~F}$ (deviation) $(1,20)=.002, \mathrm{p}=.96$ ] with the maximum delay interval responsible for the fewest shocks and the minimum postponement interval the most. (c) Shocks that resulted from the elapse of R-S intervals were curvilinearly related to the $R-S$ parameter $[F(1,20)$ $=39.2, \mathrm{p}<.0001, \mathrm{~F}($ deviation $)(2,20)=.571, \mathrm{p}=.70]$ based on the effects of the 5- and 10-sec R-S intervals. These results indicate that the three measures of shock were differently related to the principal parameter, R-S.

Shock-rate data are not usually presented on the grounds that little is added to the information provided by responserate scores. In the present case, this is obviously untrue. Under the shortest R-S interval ( $5 \mathrm{sec}$ ), when the opportunity for shock was greatest, the contribution made by $\mathrm{S}-\mathrm{S}$ shocks to the total number of shocks received, was minimal, namely $8 \%$, whereas under the longest R-S interval $(80 \mathrm{sec})$, when the fewest number of potential shocks were available, the contribution of S-S shocks to the total number of shocks received was greatest, that is, $24 \%$. This finding suggests a response pattern not indicated by the rate-of-responding measure. It justifies the use of an indirect measure of behavior, such as how effectively shock was avoided.

Avoidance (see Figure 3) is measured here in terms of the proficiency of avoidance (Hurwitz \& Bounds, 1968), 


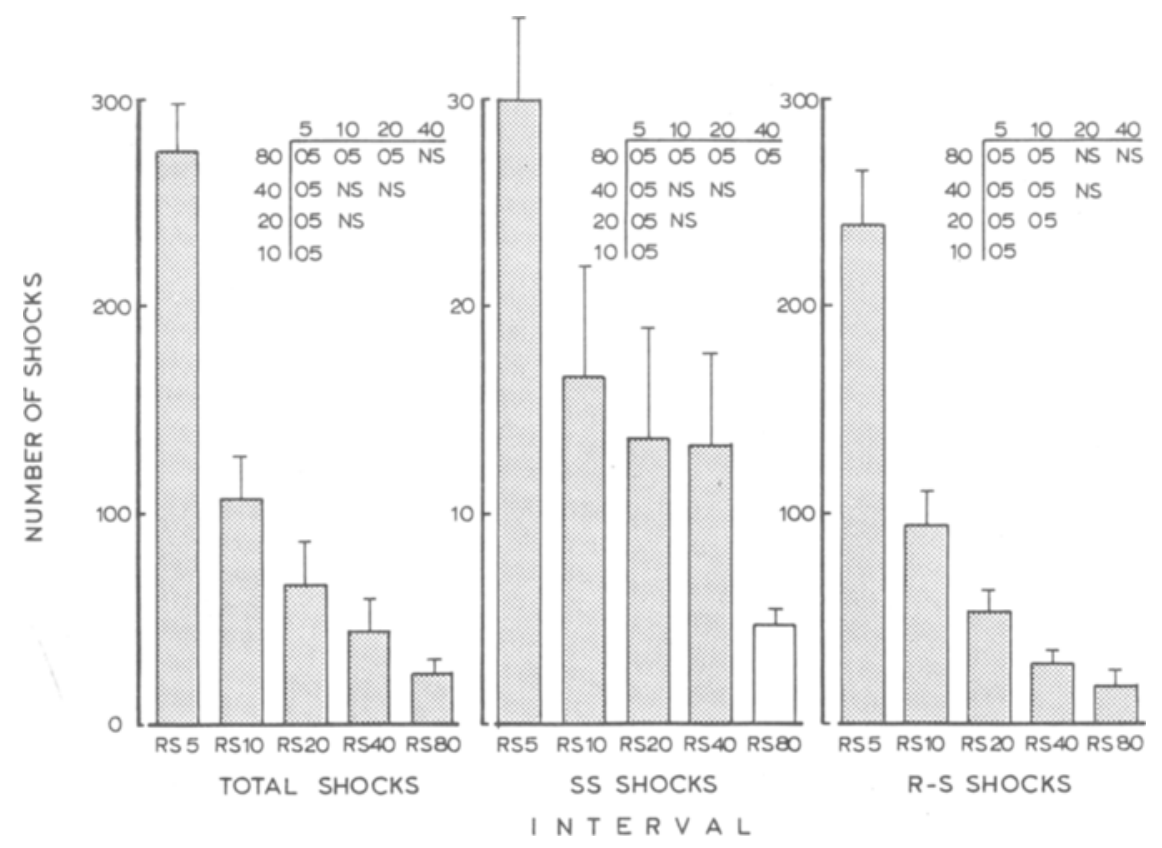

Figure 2. Shock rate as a function of R-S values. The left section refers to the total number of shocks received, the middle section refers to shocks resulting from the S-S cycle, and the right section to the number of shocks attributable to the elapse of $R-S$ intervals. Tables of significance are inserted.

which is defined as the number of shocks avoided relative to the available number of avoidable shocks. The number of avoidable shocks in a free operant situation depends on the subject's behavior. In the absence of an appropriate response, shock is administered continuously, though usually on a pulsed basis (the S-S interval). The number of avoidable shocks, however, is given by the length of the session divided by the response-initiated shock postponement interval, R-S. Total proficiency in avoidance would therefore require that none of the avoidable shocks be allowed to occur. There are different ways

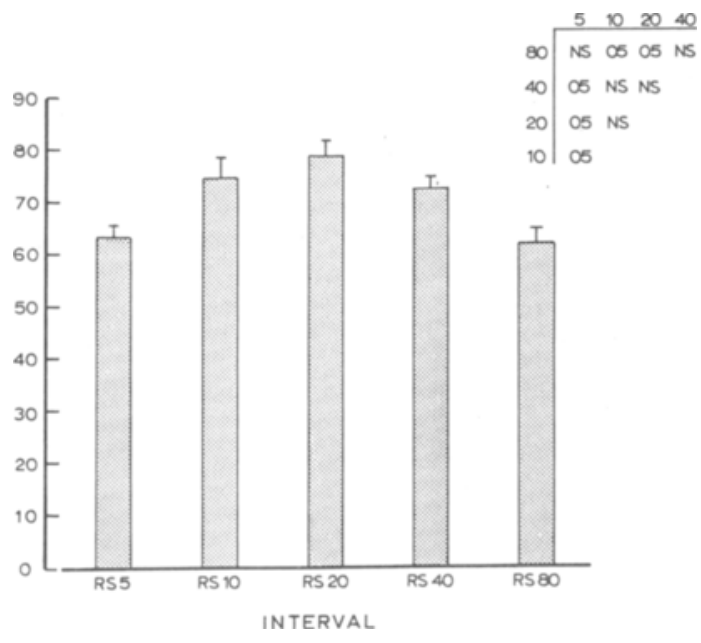

Figure 3. Percent avoidance as a function of the R-S interval. Avoidance calculated as the number of R-S shocks avoided relative to the number available. to calculate this. The method advocated by Hurwitz and Bounds (1968) for measuring is $100\left(1-S_{o} / S_{\max }\right) \mathrm{Ti}$, where $\mathrm{Ti}=(\mathrm{Ta}-\mathrm{Te}) / \mathrm{Ts}$ and where $S_{\max }=\mathrm{Ta}$ refers to the total time that the R-S interval was in operation during a session, Te to the total time that the $S-S$ interval was operative, and finally, $S_{o}$ to the number of shocks arising from the elapse of R-S periods. This method actually corrects the denominator by the amount of time attributed to the S-S interval. However, such a correction is unnecessary for well-trained subjects, since they very rarely remain in an S-S interval for more than $1 \mathrm{sec}$. Thus, even a high S-S score may not mean much in terms of the total session length. In the present instance, avoidance proficiency (Avpro) changed as a function of the shockpostponement interval $\mathrm{R}-\mathrm{S}$ and yielded an inverted Ufunction $[\mathrm{F}(1,20)=4.7, \mathrm{p}=.04, \mathrm{~F}$ (deviation) $(2,20)=$ $.175, \mathrm{p}=.84$ ]. An R-S interval of 5 and $80 \mathrm{sec}$ resulted in the least effective avoidance. In absolute terms, the number of shocks per session was significantly greater or less, respectively, than under the $\mathrm{R}-\mathrm{S}=20$ postponement interval. These results are similar to those revealed by the shock data (Figure 2), which suggests that how and when a subject responds is more important than the absolute rate of responding.

The final measure to consider is corticosteroid level (Hennessey \& Levine, 1979). The comparison involves preexperimental (i.e., basal) levels and levels under the different R-S intervals. As Figure 4 shows, corticosteroid level following experimental sessions were significantly elevated over resting basal levels $[\mathrm{F}(5,20)=1.03$, $p>.05]$, but there were no differences attributable to the R-S intervals used. 


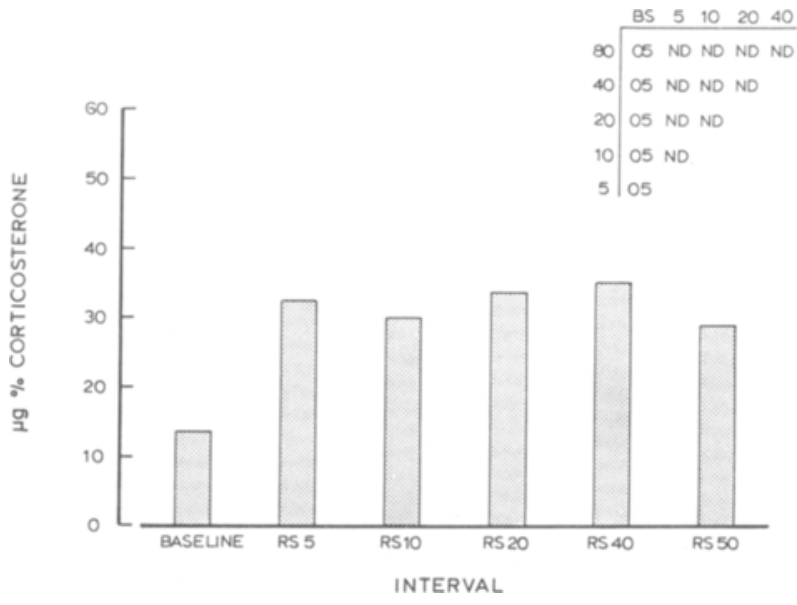

Figure 4. Corticosteroid level as a function of the R-S interval.

\section{DISCUSSION}

This study replicated previous demonstrations that the rate of responding in a free operant avoidance situation is controlled by the R-S interval (Hineline, 1977; Hurwitz, 1967; Sidman, 1966). The related finding that the frequency of shock and the size of the R-S interval correlate negatively was also confirmed. It is interesting to note not only that we were able to replicate the form of the function, but also that the values for different R-S intervals corresponded very closely to those reported in representative earlier studies (Clark \& Hull, 1966; Hurwitz \& Bounds, 1968; Hurwitz, Knapp, \& Herrmann, 1981; Leaf, 1966; Roberts, 1978; Sidman, 1953; Verhave, 1959).

However, we were not primarily interested in replicating these well-documented findings. Our concern was to examine whether the rate of avoidance was also a linear decreasing function of the R-S interval parameter, a suggestion that would follow from the often-mentioned finding that the rate of shock parallels the rate of responding as a function of the R-S interval. The results demonstrated otherwise. Rate of avoidance was nonlinear but bitonic. Avoidance deteriorated when the R-S interval was long and when it was short. It was optimal when $R-S=20 \mathrm{sec}$. This result appears to contradict the finding by Roberts (1978), who reported comparable levels of shock when R-S was 10, 20, and $30 \mathrm{sec}$. It agrees with Hurwitz et al.'s (1981) data, where a comparison was made between R-S $=20,10$, and $6 \mathrm{sec}$.

One could attribute this difference to a major difference in procedure. Roberts not only divided his subjects into groups according to the R-S interval, but also imposed an avoidance criterion that had to be met for the data to enter the statistical analysis. In the present study, each subject served under each of the R-S conditions, no criterion of avoidance was imposed, and the order effect was neutralized statistically.
The deterioration in avoidance found in this study had not been predicted. Rather, we had considered two different conflicting outcomes, the first being that the R-S would not influence the rate of avoidance, so that the function would be flat. This prediction was based on the assumption that once the subject had received training under the response-shock postponement contingency, it would generalize and transfer. In other words, what the subject would learn would be that its response on the lever was a necessary condition for maintaining a relatively shockfree situation. It may, of course, take one or two sessions before the revised parameter setting has its effect, as when a change was made in the setting from 10 to $80 \mathrm{sec}$ or, more important, from 80 to $10 \mathrm{sec}$. Such savings are entirely within the range of the subject, given that rats are able to learn a free operant avoidance task de novo under favorable conditions, within two to four relatively short sessions (Bolles \& Popp, 1964; Hineline \& Alloy, 1978; Riess, 1971; Roberts, 1978).

The second prediction was that the function would be linear because a reduction in the size of the R-S interval would be associated with an increase in the aversiveness of the situation and in its stressfulness (Gray, 1971; Weiss, 1968). It might be argued that the greater stress would facilitate previously reinforced behavior, and result in improved avoidance.

Neither of these two predictions was supported by the evidence. However, a modified version of the motivational analysis underlying the second assumption, which is based on the Yerkes and Dodson (1908) law that strong and weak motivation interferes with performance, gave a correct prediction of the results. Unfortunately, this formulation is faulty at a different level, because we found no evidence that changes in R-S interval produced motivational changes, as assumed by the theory. Specifically, postsessional corticosterone levels, which monitor the activity of the pituitary-adrenal system and which reputedly measure the physiological component of motivation (Hennessey \& Levine, 1979), were unaffected by R-S manipulations. The levels reported here are consistent with those obtained in other studies in our laboratory and do not reflect maximal values (Davis et al., 1976).

For an explanation of our result, we therefore turned to a different frame of reference. Specifically, we asked whether changes in the R-S interval resulted in changes in the topography of behavior. According to earlier results (Hurwitz, 1967), changes in the R-S interval are correlated with changes in (a) lever-contact times and (b) interlever contact intervals. The mean holding time reflects the prevailing R-S interval so that increases in R-S result in increases in mean lever holding. The function is probably a negative growth function, which implies that more and more time is spent off and, perhaps more importantly, away from the lever. Thus, the observed deterioration in the proficiency of avoidance under long R-S intervals may be due, to a large degree, to the subject's occasional absence from the critical locale of the lever. A similar anal- 
ysis applies to the deterioration of avoidance under short R-S intervals. Earlier data (Hurwitz, 1967) indicated that there was a lower limit to lever holding. It suggests an ergonomic factor that affects the minimum time required to operate a manipulandum, for example, depressing a light versus a heavy lever. A second factor is related to the phenomenon that rats often become temporarily immobilized after shock. Such freezing has its own temporal characteristics. In the leverpressing apparatus, it occurs most often on the lever, and it then counts as "leverholding," although Davis (1977) reported off-lever freezing and immobility in Campden Instruments chambers. Fanselow $(1980,1982)$, following research by Blanchard, Dielman, and Blanchard (1968), Anisman and Waller (1973), and Bolles and Collier (1976), has suggested that postshock behaviors are a conditioned form of freezing. Assuming the correctness of this interpretation, it seems reasonable that freezing increases as the frequency of shock increases (which it does under short R-S intervals). Such shock-induced freezing would contribute to nonavoidance of the next shock. It creates a vicious circle phenomenon (Mowrer, 1950), which would significantly depress the proficiency of avoidance.

In summary, our replication of Sidman's (1953) free operant avoidance experiment has demonstrated not only that the critical R-S parameter is a linear determinant of the rate of responding and of the frequency of shock, but also that it is bitonically related to avoidance, as measured by the proficiency of avoidance index. Since this index speaks directly to the central issue of the analysis of the aversive control of behavior, it should be preferred over the currently favored measure of rate of responding. Furthermore, because of its demonstrated effectiveness in detecting variables, it should at least not be ignored.

\section{REFERENCES}

Anisman, H., \& Waller, J. G. (1973). Footshock-produced excitation and inhibition of activity in rats. Animal Learning \& Behavior, 1, 93-95.

Bassett, J. R., Cairncross, K. D., \& KIng, M. G. (1972). Parameters of novelty, shock predictability and response contingency in corticosterone release in the rat. Physiology \& Behavior, 10, 901-907.

Blanchard, R. J., Dielman, T. E., \& Blanchard, D. C. (1968). Post-shock crouching: Familiarity with the shock situation. Psychonomic Science, 10, 371-372.

Bolles, R. C., \& Collier, A. C. (1976). Effect of predictive cues on freezing in rats. Animal Learning \& Behavior, 4, 6-8.

Bolles, R. C. , \& Popp, R. J. (1964). Parameters affecting the acquisition of Sidman avoidance. Journal of Experimental Analysis of Behavior, 7, 315-321.

BrunNing, J. L., \& Kintz, B. L. (1968). Computational handbook of statistics. New York: Scott Foresman.

Church, R. M. (1970). Aversive behavior. In R. Woodworth \& H. Schlosberg (Eds.), Experimental psychology (3rd ed.). New York: Holt, Rinehart, Winston.

ClARK, F. C., \& HULL, L. D. (1966). Free operant avoidance as a function of the response-shock, shock-shock interval. Journal of the Experimental Analysis of Behavior, 9, 641-647.

DAVIS, H. (1977). Response characteristics and control during leverpress escape. In H. Davis \& H. M. B. Hurwitz (Eds.), OperantPavlovian interaction. New York: Erlbaum.
Davis, H., Memmott, J., MacFaddan, L., \& Levine, S. (1976). Pituitary-adrenal activity under different appetitive extinct procedures. Physiology \& Behavior, 17, 687-690.

FANSELOW, M. S. (1980). Conditional and unconditional components of post-shock freezing. Pavlovian Journal of Biological Science, 15, 177-182.

FANSELOW, M. S. (1982). The postshock activity burst. Animal Learning \& Behavior, 10, 448-452.

Glick, D., Von Redlich, D., \& Levine, S. (1964). Fluorometric determination of corticosterone and cortisol in 0.02-0.05 milliliters of plasma or submilligram samples of adrenal tissue. Endocrinology, 74, 653-655.

GRAY, J. (1971). The psychology of fear and stress. New York: McGraw-Hill.

Hennessey, J. W., \& Levine, S. (1979). Stress, arousal and the pituitary adrenal system: A psychoendocrine hypothesis. In J. M. Sprague \& A. N. Epstein (Eds.), Progress in psychobiology and physiological psychology (Vol. 8). New York: Academic Press.

Herrnstein, R. J., \& Hineline, P. N. (1966). Negative reinforcement as shock frequency reduction. Journal of the Experimental Analysis of Behavior, 9, 421-430.

HiNELINE, P. N. (1977). Negative reinforcement and avoidance. In J. E. R. Staddon \& W. K. Honig (Eds.), Handbook of operant behavior. Englewood Cliffs, NJ: Prentice-Hall.

Hineline, P. N., \& Alloy, L. B. (1978). Warm-up effects in freeoperant avoidance in a shuttlebox. Bulletin of the Psychonomic Society, 12, 447-450.

Hurwitz, H. M. B. (1967). Lever holding under free-operant avoidance. Journal of the Experimental Analysis of Behavior, 10, 551-554.

Hurwitz, H. M. B., \& Bounds, W. (1968). Response specification and acquisition of free operant avoidance behavior. Psychological Reports, 23, 483-494.

Hurwitz, H. M. B., Knapp, T. M., \& Herrmann, T. (1981). The effect of the response-shock postponement interval on free operant avoidance by septal lesioned and normal rats. Physiology \& Behavior, 26, 135-138.

LEAF, R. C. (1966). Some effects of response consequences on Sidman avoidance acquisition. Journal of Comparative and Physiological Psychology, 61, 217-220.

Mowrer, O. H. (1950). Leaming theory and personality dynamics. New York: Ronald Press.

MunN, N. L. (1950). Handbook of psychological research on the rat. Boston: Houghton Mifflin.

RIESs, D. (1971). Shuttleboxes, Skinner boxes, and the Sidman avoidance in rats: Acquisition and terminal performance as a function of response topography. Psychonomic Science, 25, 283-286.

RoBERTS, A. E. (1978). Free operant avoidance behavior of hooded rats: Some notes on within and between-session stability. Psychological Record, 28, 253-262.

Sidman, M. L. (1953). Two temporal parameters of the maintenance of avoidance behavior of the white rat. Journal of Comparative and Physiological Psychology, 46, 253-261.

Sidman, M. L. (1966). Avoidance behavior. In W. K. Honig (Ed.), Operant behavior: Areas of research and application. New York: Appleton-Century-Crofts.

VerHave, T. (1959). Avoidance responding as a function of simultaneous and equal changes in two temporal parameters. Journal of the Experimental Analysis of Behavior, 2, 185-190.

WARNER, L. H. (1932). The association span of the white rat. Journal of Genetic Psychology, 4, 57-90.

WEISS, J. M. (1968). Effects of coping responses on stress. Journal of Comparative and Physiological Psychology, 65, 251-260.

YERKES, R. M., DoDson, J. D. (1908). The relationship of strength of stimulus to rapidity of habit-formation. Journal of Comparative Neurology and Psychology, 18, 459-482.

(Manuscript received February 28, 1984; revision accepted for publication July 20, 1984.) 